\title{
Special issue to "ICMAT 2009, Symposium F: nanostructured materials for electrochemical energy systems: lithium batteries, supercapacitors and fuel cells, June 28-July 3, 2009, Singapore"
}

\author{
Palani Balaya • San Ping Jiang • Atsuo Yamada • \\ B. V. R. Chowdari
}

Received: 14 April 2010 /Accepted: 14 April 2010/Published online: 29 May 2010

(C) Springer-Verlag 2010

\section{Preface}

Encouraged by the successes of the previous four International Conference on Materials for Advanced Technologies (ICMAT) conferences in 2001, 2003, 2005 and 2007, MRS-Singapore in association with National University of Singapore, Nanyang Technological University, Institute of Materials Research and Engineering and many other national and international institutes organised ICMAT 2009 from 28 June to 3

Palani Balaya, San Ping Jiang, Atsuo Yamada, and BVR Chowdari are the Organizing Committee members of Symposium-F, ICMAT 2009.

P. Balaya $(\bowtie)$

Department of Mechanical Engineering/Engineering Science

Programme, Faculty of Engineering, Block E3A, \#04-23,

National University of Singapore,

7 Engineering Drive 1,

Singapore, Singapore 117574

e-mail: mpepb@nus.edu.sg

\section{S. P. Jiang}

School of Mechanical and Aerospace Engineering,

Nanyang Technological University,

50 Nanyang Avenue,

Singapore, Singapore 639798

\section{A. Yamada}

Department of Engineering, The University of Tokyo,

Building 5-607, 7-3-1 Hongo, Bunkyo-ku,

Tokyo 113-8656, Japan

B. V. R. Chowdari

Department of Physics, National University of Singapore,

BLK S12, Lower Kent Ridge Road,

Singapore, Singapore 117542
July 2009 at the SUNTEC Singapore International Convention and Exhibition Centre.

On 28 June 2009, the conference started with traditional inaugural event followed by a plenary talk by Prof. Peter Gruenberg, a Noble Laureate in Physics. There were more than 2,000 members of the international scientific and materials research community representing over 40 countries that attended 23 Symposia covering many frontier areas in materials science and technology. The overall level of participation in this conference was of an exceptionally high standard as evidenced by the participation of various Nobel Laureates who gave plenary and public lectures, distinguished keynote and invited speakers.

The Symposium F on "Nanostructured Materials for Electrochemical Energy Systems: Lithium Batteries, Supercapacitors and Fuel Cells" provided an excellent opportunity for interdisciplinary forum addressing recent trends of science and technology related to materials for electrochemical power sources. It had attracted large participation of up to 150 , including 41 invited talks, 60 oral presentations and 50 poster presentations. The talks were classified under three broad categories, which are as follows: electrodes (cathodes and anodes) and electrolytes of lithium batteries, supercapacitors and fuel cells. To manage such large number of presentations, two parallel sessions were scheduled, one dealing with largely lithium batteries and the other addressing fuel cells and supercapacitors. Two best poster awards were given based on the recommendation of jury members.

On behalf of the organising committee, we would like to thank all the invited speakers, session chairs and 
the sponsoring agents for the success of the Symposium F during ICMAT 2009. A special issue proceedings in the "Journal of the solid state electrochemistry" was planned to publish peer reviewed manuscripts presented in the symposium. Thanks to all the authors who have submitted their manuscripts within the due date and the reviewers for their valuable suggestions and comments to improve the quality of the manuscripts. We also thank the Editor-in-Chief, Prof. Fritz Scholz, for the timely release of the online first publication and the publication of the proceedings volume in a short period of time. 